ÚlTIMA DÉCADA, N47, DICIEMBRE 2017, PP. 183-

\title{
LA PRESENTACIÓN DICOTÓMICA DEL ESPACIO ESCOLAR EN LOS DISCURSOS MEDIÁTICOS
}

\author{
VIRGINIA SAEZ ${ }^{1}$
}

\begin{abstract}
RESUMEN
Este artículo presenta un estudio exploratorio que analiza la presentación dicotómica de los episodios de violencia en las escuelas en los discursos mediáticos, en Argentina en el período 1993-2011. Dadas las características del objeto de indagación el abordaje metodológico fue cualitativo y la información se analizó en el marco del análisis socioeducativo del discurso. Entre los resultados observamos que se construye una representación diferenciada entre las víctimas y los victimarios. Se alude a la víctima desde una cercanía social que propicia la identificación con su figura. Concluimos que la presentación dicotómica forma parte de una dinámica de estigmatización social.
\end{abstract}

PALABRAs ClaVe: VÍCTIMA, VICTIMARIO, ESCUELA, MEDIOS DE COMUNICACIÓN, VIOLENCIA.

1 Doctora en Educación y Magister en Educación, Pedagogías Críticas y Problemáticas Socioeducativas por la Facultad de Filosofía y Letras (FFyL), Universidad de Buenos Aires (UBA). Becaria posdoctoral del Consejo Nacional de Investigaciones Científicas y Técnicas (CONICET). Desarrolla sus investigaciones en el marco del Programa de Investigación sobre Transformaciones Sociales, Subjetividad y Procesos Educativos. Dir. Carina V. Kaplan. Sede: Instituto de Investigaciones en Ciencias de la Educación (IICE), Facultad de Filosofía y Letras (FFyL), Universidad de Buenos Aires (UBA). Correo electrónico: saezvirginia@hotmail.com 


\title{
A APRESENTAÇÃO DICOTÔMICA DO ESPAÇO ESCOLAR NOS DISCURSOS MEDIÁTICOS
}

\begin{abstract}
RESUMO
Este artigo apresenta um estúdio exploratório que analisa a apresentação dicotômica dos episódios de violência nas escolas nos discursos mediáticos, na Argentina no período de 1993 - 2011. Dadas as características do objeto de indagação a abordagem metodológica foi qualitativa e a informação foi analisada no marco da análise socioeducativa do discurso. Entre os resultados observamos que é construída uma representação diferenciada entre as vítimas e os algozes. Refere-se à vítima desde uma proximidade social que propicia a identificação com sua figura. Concluímos que a apresentação dicotômica é parte de uma dinâmica de estigma social.
\end{abstract}

PalaVRas-ChaVe: Vítima, ALgOZ, ESCOLA, MeIOS DE COMUNICAÇÃO, VIOLÊNCIA.

\section{THE DICHOTOMOUS PRESENTATION OF THE SCHOOL SPACE IN MEDIA DISCOURSES}

\begin{abstract}
This article presents an exploratory study on the dichotomous presentation of the episodes of school violence in the media discourses of Argentina during the period 1993-2011. Given the characteristics of the object of inquiry, the methodological approach was qualitative, while the information was analyzed from the perspective of the socioeducational discourse analysis. Among the results, we observed differences between the representation of the victims and the perpetrators, with the victims being referred from a social closeness that favors identification with their figures, therefore concluding that this dichotomous presentation is a part of a dynamic of social stigmatization.
\end{abstract}

KEYWORDS: VICTIM, PERPETRATOR, SCHOOL, MASS MEDIA, VIOLENCE. 


\section{INTRODUCCIÓN}

Los medios de comunicación participan de la construcción social de la experiencia juvenil y estudiantil. El periodismo cuenta con una posición privilegiada en la producción de discursos sociales dado que dispone de los medios más potentes para hacerlos circular e imponerlos (Bourdieu, 2002). Las noticias periodísticas, en tanto construcciones de la realidad (Verón, 1987), producen y reproducen principios de visión y división del mundo social. Los modos por los cuales la prensa construye el vínculo entre violencia y escuela como parte de una agenda mediática generan efectos que reproducen discursos e imágenes sobre la escuela y los sujetos que la habitan (Bourdieu y Wacquant, 2005).

Los jóvenes constituyen una población particularmente afectada por la violencia. Según estadísticas nacionales, la mayoría de víctimas y victimarios en situaciones de violencia pertenecen a este grupo social. En el contexto argentino, ${ }^{2}$ según los análisis efectuados por el Observatorio de Jóvenes Comunicación y Medios de la Universidad Nacional de La Plata (2009; 2011), se verifica un aumento de los enunciados que vinculan a los jóvenes con hechos de violencia, ya sea como víctimas o victimarios. El crecimiento de formas delictivas a la par del aumento de lo que se denomina, desde una perspectiva de análisis de la sensatez penal (Waqcuant, 2010), como sentimiento de inseguridad se ha convertido en uno de los temas sociales con más peso en las agendas de los gobiernos y de los medios de comunicación (Pegoraro, 2000;

\footnotetext{
${ }^{2}$ En la última década, la temática de las violencias en el ámbito escolar se ha instalado en las agendas públicas como una problemática socialmente relevante. Dan cuenta de ello, la creación del "Observatorio Argentino de Violencia en las Escuelas" dependiente del Ministerio de Educación de la Nación Argentina, en 2004. Por su parte, la Ley Nacional de Educación (Ley 26.206) tiene entre sus objetivos "promover la resolución pacífica de conflictos". Junto con estas, en 2013 ha sido promulgada la "Ley para la promoción de la convivencia y el abordaje de la conflictividad social en las instituciones educativa” (Ley 26.892).
} 
Kessler, 2009; Míguez e Isla, 2010). ${ }^{3}$ Numerosas investigaciones analizan cómo los medios de comunicación colaboran en construir sentidos sobre la criminalización de los jóvenes (Rey, 2005; Cerbino, 2012; Saintout, 2013). Esta operación semántica no se realiza por igual para todos los jóvenes sino fundamentalmente para aquellos que forman parte de los sectores socialmente desfavorecidos cuyas conductas y expresiones entran en conflicto con el orden establecido desbordando los modelos de juventud legitimados (Urresti, 2000; Balardini, 2004; Chaves, 2005). Así también, se vislumbra un discurso dual sobre los jóvenes: por un lado, son percibidos como la promesa del futuro, y al mismo tiempo, se los asemeja a criminales violentos que ponen en peligro la supuesta tranquilidad social (Kaplan, 2012b). Estas prácticas discursivas imponen una doxa penalizante que "...tiene una de sus expresiones más brutales en el par taxonómico violento-pobre.” (Kaplan, 2011: 97). Los procedimientos enunciativos de las noticias se convierten en una ocasión propicia para que los medios masivos de comunicación pongan en escena la figura mediática del joven (varón) de sectores socialmente desfavorecidos asociado a la violencia y al delito (Gentili, 2011).

El tratamiento de los episodios violentos que realizan los medios de comunicación se apoya sobre la mirada dicotómica de víctima- victimario dificultando en los lectores la generación de una representación superadora (Valdemarca y Bonavitta, 2011; Saez, 2013).La asunción de la idea de la víctima es interpretable desde su condición relacional. Si utilizamos el término "víctima" es necesario tener presente que en todos los casos se está caracterizando a una relación: no hay una persona o grupo que sea "víctima" por naturaleza sino que lo distintivo es llegar a ser tal por una vinculación social, y por tanto es sobre esta última que pueden operarse cambios. Las

3 Una serie de investigaciones muestran que la "sensación de inseguridad" no siempre coincide con los parámetros objetivos que dan cuenta de la cantidad de delitos. Una apreciación cuidadosa de esta problemática revela que no es solo una mayor frecuencia de delitos lo que hace que se propague la sensación de inseguridad, sino que hay otros aspectos asociados a ello, entre otros los medios de comunicación. (Míguez e Isla, 2010; Kessler, 2009; Pegoraro, 2000). 
víctimas son individuos en sociedad que participan de ciertas configuraciones epocales (Debarbieux, 2002).Por tal motivo, es necesario indagar en la construcción de la víctima y de los acontecimientos disruptivos que expone el periodismo como lugares densamente cargados de significado y visibilidad (Reguillo, 2006). La autora menciona cómo "el nuevo periodismo" es narrado por la víctima para conquistar un lugar sin mediaciones, la nota cruda, la voz que proviene de la auténtica experiencia límite, y la que garantiza el zapping favorecedor. Observa el lugar de la víctima como un secuestro mediático y parte de la banalidad contemporánea.

La racionalidad de la comunicación como un proceso performativo, los modos de decir, representar y metaforizar los acontecimientos disruptivos. En una lucha por la producción de visibilidad, las estrategias simbólicas que organizan los rituales, las protestas, generan una disputa por la elaboración y apropiación del imaginario en torno al acontecimiento. La presencia mediática en los acontecimientos suelen hacer un zoom in, enfocando a determinados actores y fijándolos en el lugar "de la víctima”. A través de la construcción mediática del acontecimiento, el signo fundamental se organiza en torno al aislamiento de la causa "única", y a determinados sujetos se los coloca en el lugar de "monstruo". Entonces, más allá de la descripción de un suceso fatídico, lo fundamental se centra en los lenguajes-soportes que vehiculizan el sentido del acontecimiento. Pese a estrategias diferenciales de producción de visibilidad, en lo que toca a la racionalidad comunicativa, los acontecimientos suelen quedar atrapados en el lenguaje de lo numinoso, de la justicia vengadora, sus protagonistas devienen “dolientes" o "comunidad de sufrientes" (Goffman, 2001), lo que diluye la identidad ciudadana del colectivo.

Los discursos de los medios de comunicación sobre las violencias en las escuelas hacen sonar la alarma educativa. Se trata de discursos que circulan por dentro y por fuera de la escuela (Lahire 1999). Sostenemos que lo que se piensa y se dice públicamente sobre la educación no sólo connota las miradas de 
quienes comentan sobre ella sino que, convertido en el sentido común pedagógico de directivos, docentes, padres y alumnos, también atraviesa las decisiones cotidianas del mundo escolar (Finocchio 2009). Dados estos antecedentes, resulta relevante analizar la presentación dicotómica del par víctima-victimario en los discursos mediáticos de violencia en las escuelas. En tanto sostenemos como hipótesis inicial que dicha mediatización tiene efectos simbólicos sobre los procesos de estigmatización de estos actores escolares. Lo que se piensa y dice públicamente sobre la educación incide en la cotidianeidad de la tarea escolar y abonan a la conformación de identidades sociales.

\section{ENFOQUE TEÓRICO Y METODOLÓGICO}

Toda práctica social está conformada por una serie de momentos, algunos de los cuales son discursivos y otros no (Fairclough, 2008). En este trabajo, sostendremos que algunas prácticas sociales son eminentemente discursivas y entre ellas ubicamos las prácticas periodísticas. De este modo, entendemos que dichas prácticas atraviesan las coyunturas de modos particulares, construyen de esta manera, algunos de los momentos discursivos de toda práctica. Sin embargo, el fundamento de este trabajo es el análisis del discurso de los medios entendidos como “máquinas de producción de realidad social” (Verón, 1987: 7). No pretendemos sostener con esto que las lo que se presenta en las coberturas sean pura ficción mediática. Tampoco vamos a afirmar que las prácticas periodísticas nos acercan diariamente a una copia fiel de la "realidad de los hechos". Se trata, en todo caso, de que producen aquello que consumimos cotidianamente como actualidad. Una prueba de ello es que solamente algunos acontecimientos devienen en noticia. Por el contrario, parecería que sólo una vez que los medios "hacen” noticia de un determinado acontecimiento, éste logra trascender sus propios límites espacio-temporales: sus prácticas y protagonistas se vuelven públicos y esta “publicidad” suscita 
otras series de prácticas discursivas y no discursivas. También se asume que, si bien no quedará demostrado en este trabajo, las representaciones sociales que ofrecen los medios no son uniformes ni estables (Raiter y Zullo, 2008). Desde este punto de vista en etapas posteriores del análisis, esperamos encontrar diferencias en la presentación de los hechos y de sus protagonistas entre estos y otros matutinos y, al mismo tiempo, cambios en un mismo medio al pasar de un conflicto a otro.

Desde una perspectiva socioeducativa consideramos que las violencias en las escuelas no son un correlato mecánico de la violencia social, aunque es allí donde se originan y cobran su sentido más hondo. Ciertas mediaciones intervienen en la escuela para que esta posibilite algo distinto que los comportamientos brutales que suscitan las sociedades capitalistas salvajes (Kaplan, 2009). El objetivo de este estudio consistió en analizar e interpretar la presentación dicotómica del par víctima-victimario en los discursos mediáticos de los episodios de violencia en las escuelas en la prensa platense en el período 1993-2011. Este trabajo no trata de dar cuenta de los hechos ocurridos sino de la reconstrucción de los mismos que presentaron los periódicos elegidos. Rastrear las formas discursivas de construcción de estos acontecimientos particulares.

Se delimitaron como unidades de análisis los discursos presentes en las coberturas sobre las los episodios de violencia en las escuelas en los diarios El Día, Hoy, Extra y Diagonales de la ciudad de La Plata en el período 1993-2011. El corpus se conforma por 3581 notas. El año de inicio del relevamiento fue seleccionado dado que en 1993 se sanciona la Ley Federal de Educación 24.195. Esta normativa constituye un hito relevante por ser la primera ley que regula el sistema educativo argentino en su conjunto, y establece diez años de educación obligatoria para los ciudadanos, desde la sala de 5 años hasta noveno año del nivel primario. 
Es necesario destacar que se eligen los medios gráficos dado que son una referencia dominante y marcan tendencia informativa para el resto de los medios de comunicación (Bonilla Vélez y Tamayo Gómez, 2007) y porque interesa la materialidad de los diarios y la potencialidad del texto escrito para observar las distintas formas de nominación del fenómeno. Se seleccionaron los medios de la ciudad de La Plata porque es la capital de la provincia de Buenos Aires y es considerada su principal centro político, administrativo y educativo. Estas características la hacen significativa del presente estudio, por ser un espacio social a partir del cual se toman decisiones que afectan a todas las provincias de la república Argentina.

El abordaje metodológico es cualitativo, y el diseño de investigación asume un carácter exploratorio. El muestreo es finalístico: se seleccionaron las prácticas discursivas que aportaran información de interés en relación al objetivo estipulado. El estudio nos permitió analizar el objeto de estudio en el período comprendido entre 1993 y 2011. No se pretendió analizar cómo han ido modificándose las representaciones mediáticas a lo largo del lapso elegido sino observar las continuidades en la caracterización de la presentación dicotómica del par víctima-victimario en los discursos mediáticos sobre las violencias en las escuelas. Esto nos brindó bases connotativas para describir el fenómeno. Hemos abordado todas las secciones de cada periódico. En el conjunto hallamos gran cantidad de semejanzas y pocas diferencias, por tal motivo no se realizó una distinción analítica por cada diario.

Ahora bien, como se demostró en trabajos anteriores (Saez, 2015) existen tensiones y debates presentes en los estudios sobre medios de comunicación que abordan temáticas sociales. Desde las corrientes de la Lingüística Critica (Raiter y Zullo, 2008) y del Análisis Crítico del Discurso (Van Dijk, 2007) evidencian que no hay una forma única de abordar los discursos mediáticos y manifiestan su preocupación por la reproducción de la desigualdad. En afinidad con esta preocupación pero distanciándose de un abordaje lingüístico- 
discursivo con el encuadre metodológico del Análisis Crítico del Discurso y de la Lingüística Crítica, la presente investigación realizó el tratamiento de los datos en el marco del análisis socioeducativo del discurso (Martín Criado, 2014). Esta metodología es de relevancia para “...dilucidar el juego de tensiones y ambivalencias en que se mueven prácticas y discursos (...) y ver las estrategias simbólicas para legitimar o deslegitimar a los distintos sujetos y sus prácticas -de ahí el énfasis en situar todo discurso en un espacio de discursos y todo enunciado en la estrategia general de presentación de sí" (Martín Criado, 2014: 133). La línea de análisis que se sigue postula una interrelación entre las noticias y la práctica social que los produce, por eso referiremos a práctica discursiva. Desde esta perspectiva el uso de ciertos actos de nombramiento y clasificación en las notas estará determinado por las convenciones socialmente aceptadas para el discurso en el que se inserta. A su vez, los límites de ese discurso estarán relacionados con las condiciones de reproducción/transformación que posibilitan las estructuras sociales existentes. El desafío consistió en establecer dimensiones de descripción y análisis para elucidar el tratamiento de la presentación dicotómica del par víctima victimario en los discursos mediáticos de los episodios de violencia en las escuelas.

Respecto a la contextualización de los discursos, es relevante mencionar que las notas analizadas estuvieron atravesadas por una temporalidad educativa particular, en la cual se extendió la escolaridad obligatoria de los jóvenes argentinos. En 1993, en la Ley Federal de Educación se extiende la obligatoriedad a octavo y noveno año, y en 2006, ${ }^{4}$ en la Ley de Educación Nacional se establece, en su artículo 16, la amplitud de su obligatoriedad desde el preescolar hasta el nivel secundario, situación que produjo un considerable

\footnotetext{
${ }^{4}$ Deben mencionarse también la ley 25.864 que establece un mínimo de 180 días de clase anuales, la ley 26.075 que exige el incremento anual en el gasto destinado a la educación, ciencia y tecnología, y la ley 27.045 que establece la obligatoriedad escolar desde los cuatros años de edad hasta cumplir el ciclo secundario.
} 
aumento de la matrícula escolar en todo el país. ${ }^{5}$ Estos aspectos son relevantes en la lucha simbólica por la representación de la escuela y los estudiantes. Como parte de los propósitos de la investigación, se encuentra la intención de contribuir a una alternativa teórica y práctica frente a aquellas visiones estigmatizantes que portan y operan desde una mirada de las escuelas y los estudiantes como lugares y sujetos peligrosos de los cuales habría que resguardarse.

Es pertinente especificar cómo se realizó el estudio de las caricaturas y fotografías presentes en las coberturas. En un primer momento se examinó el nivel morfológico y el nivel compositivo de los mismos sin limitarse a una interpretación inmanente sino que se analizó la concepción socioeducativa que se expresa a través de estos niveles, conformando un estudio global. Como sostiene Amalia Barbosa Martínez “el método documental no solamente supone la superación de un análisis formal e inmanente, sino también la superación de una análisis autónomo” (Barbosa Martínez, 2006: 400).

\section{EL PROCESO DE CONSTRUCCIÓN DEL DISCURSO DICOTÓMICO}

\subsection{EL TRATAMIENTO DE LA VÍCTIMA Y EL VICTIMARIO EN LOS DISCURSOS MEDIÁTICOS}

Los alumnos, tal como son narrados por la prensa gráfica de La Plata, son víctimas y victimarios de situaciones de violencias en el espacio escolar. Se construyen dos bandos: los atacantes y las víctimas:

“Alumno de la Secundaria $N^{0} 8$ baleó a un compañero en plena clase de inglés”. (El Día, 22-03-2011)

${ }^{5}$ Según datos proporcionados por la Dirección Nacional de Información y Estadística Educativa, dependiente del Ministerio de Educación y Deportes de la Nación la matrícula total de alumnos en el año 2007 era de 11.262.362, mientras que, en el año 2015, dicha suma ascendía a 12.536.492 (Boero y Guadagni, 2015). 
“Amenazó con matar a todos sus compañeros de colegio”. (Hoy, 21-062011)

“Alumno disparó a su compañera”. (Extra, 08-11-2011)

"Un niño correntino y una adolescente de Mar del Plata tras recibir golpizas fueron internados. La ola de violencia escolar parece no tener fin”. (Diagonales, 14-08-2008)

$\mathrm{Al}$ construirse la figura del victimario se utilizan recursos enunciativos que resaltan la distancia simbólica. Cuando se trata de violencia en el espacio escolar, el relato mediático generalmente parte de la certeza de la inculpación, aun sin basarse necesariamente en alguna prueba, para pasar con el correr del tiempo a la presunción o a la desmentida. Un caso significativo fue la cobertura de un episodio en el Normal $\mathrm{N}^{\circ} 3$, en la que aparece el titular: "El Normal $\mathrm{N}^{\circ} 3$ movilizado por estudiante armado" (El Día, 10-06-2011) y a partir del cual puede llegar a pensarse en la presencia de un accidente. Pero posteriormente se aclara que "el arma le fue entregada por una persona que pasó corriendo por la puerta del establecimiento secundario y que él, asustado y sin saber qué hacer, la guardó tal como estaba, envuelta en una gorra, y la ingresó al aula” (El Día, 16-06-2011).

Por otro lado, en la construcción del victimario se atribuye en muchos casos este lugar al accionar de alumnos en "bandas". Dentro de los estereotipos conformados sobre el alumno violento-alumno no violento se observaron mecanismos de inclusión-exclusión de la violencia según dos modelos de juventud. Por un lado, los estudiantes, alumnos en los que prevalece su identidad educativa, y por otro, los excluidos, los que se agrupan en bandas, patotas.

"Ahora no. En este mundo en donde los limites se han diluido hasta hacerse imperceptibles, es habitual la pelea de todos contra todos, 
mientras los demás trepan a los puentes del Centenario para no perder detalle y alentar a uno de los grupos en pugna”. (El Día, 18-08-1993)

"Según la magistrada, el hecho se produjo por 'una pelea entre dos banditas de la escuela'. El preadolescente es alumno de la EGB $\mathrm{N}^{\mathrm{o}} 78$, ubicada en 13 y 42. El miércoles, la directora de la escuela dio aviso a la policía cuando fue alertada de que el menor portaba un cuchillo y estaba dispuesto a pelearse. Afortunadamente, los efectivos lograron interceptarlo antes”. (Hoy, 14-10-2005)

"El miedo por los hechos de violencia entre bandas juveniles no se disipó en el ex Normal No 3”. (Diagonales, 25-06-2011)

"Se trata de un nuevo modo de violencia que cultivan chicos, que es que se agrupan en bandas y se pelean entre sí. Pertenecen a distintas escuelas, por eso creo que los gabinetes de cada una debieran trabajar en conjunto para terminar con el problema”. (Diagonales, 16-06-2011)

"Una bandita de chicos golpeó a una compañera de colegio por ser paraguaya”. (Hoy, 07-06-2011)

Ahora bien, cuando se nombra y alude a la figura de la víctima los medios dan cuenta de una cercanía social, moral, y hasta afectiva, que propicia la identificación con el actor. Para ello observo una serie de recursos particulares: se presentan voces de los familiares de las víctimas y se construye un “nosotros” que incluye a los lectores. En las coberturas de violencia y escuela, como ya lo menciona Reguillo (2006), las víctimas son lugares densamente cargados de significado y visibilidad. Esto será evidente en las fotos que se presentan, en las que se representa a la víctima en el centro de la escena.

En el caso de la Masacre de Río de Janeiro el atacante fue nombrado por las coberturas periodísticas como: “ex alumno”, “atacante”, “agresor”, “joven/esquizofrénico”, “alucinado”, “persona furiosa y trastornada”, “matador”, “asesino”, “pistolero”, “homicida”. Cuando el enunciador construye la 
representación de la violencia el agresor permanece invisibilizado, al tiempo que puede ocupar el lugar de víctima de una patología o el de un ser irracional, escasamente responsable de sus actos. La posición del victimario es ponderada en un marco que permitiría justificarlo y lo ubica sin autonomía.

Por otro lado, expresaban que "Familiares y amigos de los doce niños asesinados ayer en una escuela de Río de Janeiro despiden hoy los restos de las víctimas" (Hoy, 08-04-2011) y que "Fue conmovedora la asistencia de compañeros de los estudiantes” (El Día, 09-04-2011). Así, las prácticas discursivas hacen mayor énfasis en las nominaciones que aluden al joven violento-alumno violento que en aquellas que señalan al joven no violentoalumno no violento, como sostiene Carina Kaplan, "la diferencia en tanto subalternidad se expresa en la negatividad" (2008b: 147). De esta manera se construye discursivamente la existencia de alumnos no violentos (víctimas de los hechos de violencia en la escuela) y alumnos violentos (victimarios de los hechos de violencia en la escuela), como una manera de reforzar la idea de maldad individual (o bondad individual) producto de una elección. Esto se verá reflejado en las caricaturas que aparecen en las coberturas del diario Hoy a través de representaciones de enfrentamientos como las que se presentan a continuación: 
Imagen 1

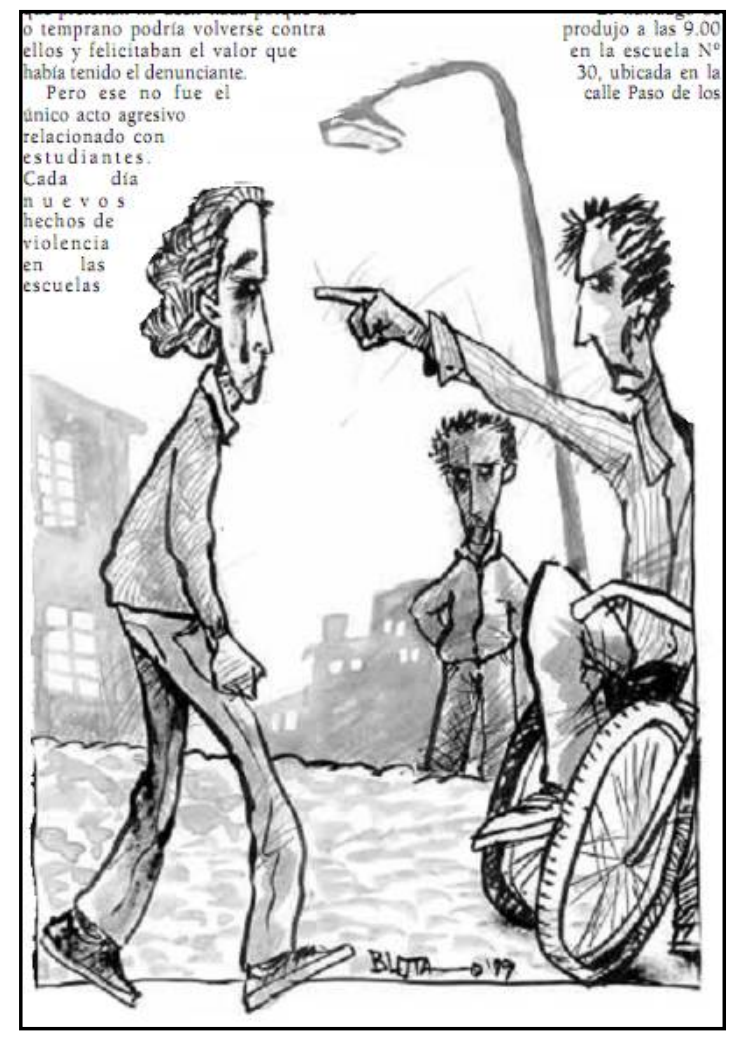

(Hoy, 12-06-1999)

Imagen 2

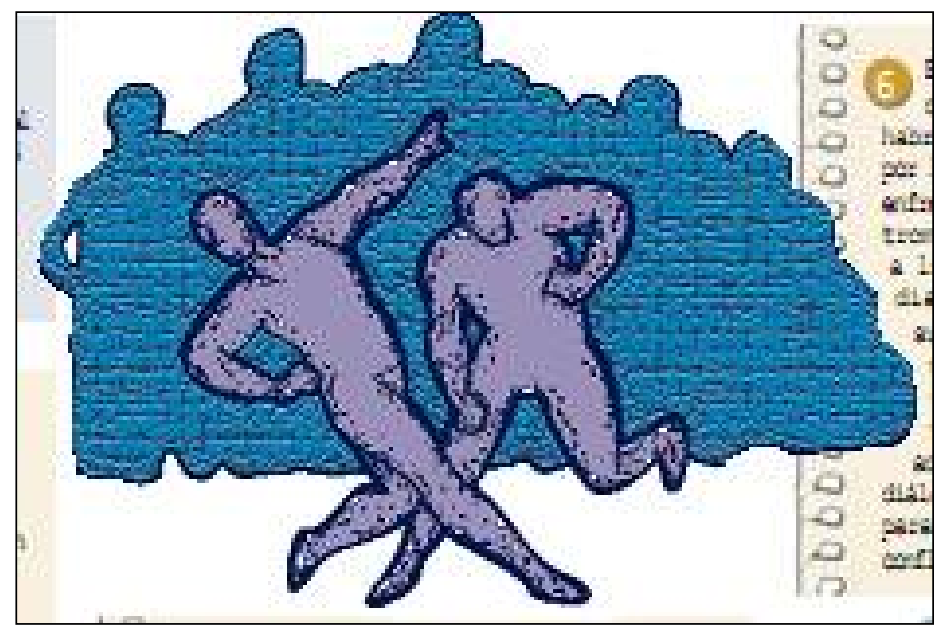

(Hoy, 15-09-1999) 
Imagen 3

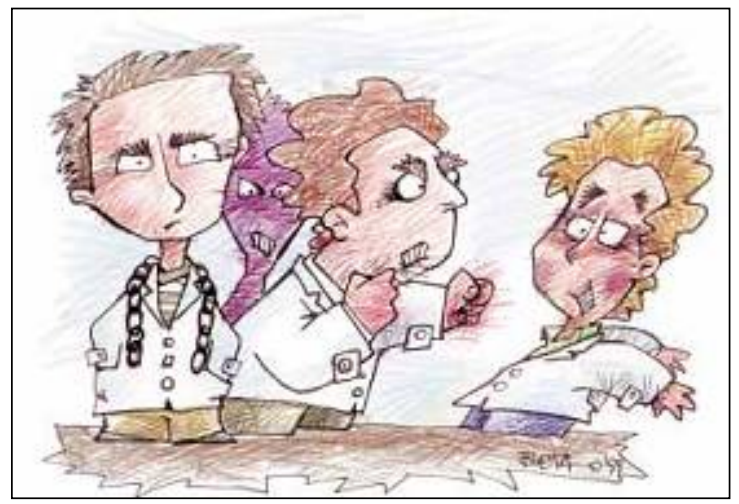

(Hoy, 29-05-1999)

\subsection{LAS ESTUDIANTES COMO VICTIMARIAS DE LA VIOLENCIA}

Otro aspecto relevante en la construcción del par víctima-victimario que aparece desde el 1998 es la presencia de mujeres como victimarias de los episodios de violencia en el espacio escolar. Las prácticas discursivas del corpus abordado son un espacio investido por el poder simbólico, carente de neutralidad y, por lo tanto, creador y legitimador de identidades sociales jerarquizadas. En este espacio se dan luchas simbólicas donde se disputan los sentidos de lo femenino y lo masculino, donde, además de transmitir, se negocian saberes respecto del género.

En las coberturas sobre la violencia en los espacios escolares aparecen continuidades y rupturas con los estereotipos hegemónicos sobre las mujeres. Aparecen como continuidad de los sentidos hegemónicos: el lugar de fragilidad femenina, el vínculo con la belleza y la mirada del otro y el énfasis en la rivalidad entre mujeres. Las operaciones discursivas siguen poniendo a las mujeres en un lugar de subordinación y de víctima. En situaciones donde se involucran alumnos y alumnas, las escolares son víctimas de la situación violenta. Se las presenta como frágiles y vulnerables, reproduciendo de esta manera las identidades hegemónicas para las estudiantes. 
"Piden detención de docente catamarqueño por presunto abuso sexual. La Justicia de Catamarca ordenó la detención de un docente de la Escuela Municipal de la localidad de Fray Mamerto Esquiú, ubicada a unos 20 kilómetros al norte de la capital provincial, por 'presunto abuso sexual de dos alumnas de 9 y 10 años’, informaron fuentes policiales y judiciales”. (Hoy, 18-04-2011)

"Una bandita de chicos golpeó a una compañera de colegio por ser paraguaya”. (Hoy, 07-06-2011)

“Nena víctima de la xenofobia: la escuela organizará talleres especiales”. (Hoy, 08-06-2011)

Pero aparece como ruptura la figura de la alumna violenta, donde se observa un cambio en la identificación femenina con la pasividad y la amabilidad. Se construye y transmite esta figura como aquella que rompe con los estereotipos sociales hegemónicos sobre las mujeres. En la mayor parte de las notas se trata de enfrentamientos en los que no participan varones. Los motivos de los enfrentamientos son exclusivamente por chicos o por ser linda, lo cual sigue reproduciendo la mirada social sobre las mujeres que dicta que deben estar lindas y preparadas para satisfacer a otros y que la única preocupación por la que se pueden enfrentar son los temas relacionados con hombres.

“Avellaneda: golpearon a una alumna para subir el video a Internet. Una nena de 12 años fue golpeada por un grupo de compañeras en el medio del colegio y la filmaron para subir el video en Internet”. (Hoy, 24-112011) 
“Una alumna de 15 años llevó un revólver 22 a la escuela de Punta Lara. Había amenazado con usarla contra la novia de otro joven. Este menor ingresó, se la arrebató y la entregó a las autoridades”. (Hoy, 19-05-2011) ${ }^{6}$ “Ramos Mejía: adolescente de 15 apuñaló a una compañera de colegio”. (Hoy, 02-06-2011)

“Una alumna de 15 apuñaló a otra”. (Hoy, 03-06-2011)

"Rosario: alumna fue agredida de una cuchillada por una compañera”. (Hoy, 12-05-2011)

“Una adolescente de 16 años fue asesinada de dos puñaladas en el corazón por la madre de otra chica de 14 que salió en defensa de su hija, cuando ambas peleaban en el pasillo de un edificio de Ciudad Evita a raíz de una disputa que había comenzado días atrás por un chico, en la red social Facebook”. (Hoy, 24-11-2011)

“Le pegaron por ser linda”. (Hoy, 14-11-2011)

Para finalizar es necesario destacar que las coberturas de los episodios de violencias en el espacio escolar reproducen los esquemas de percepción y apreciación y expresan el estado de las relaciones de poder simbólico (Bourdieu, 1988).

\subsection{LA PRESENTACIÓN DE LAS VÍCTIMAS DESDE LA COBERTURA FOTOGRÁFICA}

En este apartado se analizan las imágenes presentes en las coberturas sobre las violencias en el espacio escolar. La construcción informativa basada en fotos favorece la conformación de la verdad como dato "objetivo” hallable

\footnotetext{
${ }^{6}$ En este caso las agredidas también son mujeres, aspecto que por el momento se dejará de lado para ser tratado más adelante en el trabajo.
} 
en la realidad. En esta operación comunicativa los modos de decir de un medio de comunicación devienen, a la vez, verosímiles y realistas.

Sin embargo, como sostiene Norbert Elias, “...la visión alcanza una significación absolutamente específica en la sociedad civilizada” (2009: 296), en tanto no es el ojo en cuanto instrumento anatómico aislado el que ve; la mirada divide y hace inteligible el espacio. La forma de mirar y su expresión en las imágenes son constitutivas de un habitus:

Las instrucciones más determinantes para la construcción del habitus se transmiten sin pasar por el lenguaje ni por la conciencia, a través de sugestiones que están inscritas en los aspectos más aparentemente insignificantes de las cosas, las situaciones o prácticas de la existencia ordinaria: así los modales, la forma de mirar, de estar, de guardar silencio, incluso la forma de hablar ("miradas reprobadoras", "tonos" o "aires de reproche”, etc.) están cargados de conminaciones que son tan difíciles de revocar, tan poderosas, precisamente porque son silenciosas e insidiosas, insistentes e insinuantes. (Bourdieu, 2014: 30-31)

En el corpus relevado se observa la presencia de imágenes en relación a la construcción del par víctima-victimario. Cuando se nombra y alude a la figura de la víctima los medios dan cuenta de una cercanía social, moral, y hasta afectiva, que propicia la identificación con el actor. Para ello observo una serie de recursos particulares: se presentan voces de los familiares de las víctimas y se construye un "nosotros" que incluye a los lectores. En las coberturas de violencia y escuela, como ya lo menciona Reguillo (2006), las víctimas son lugares densamente cargados de significado y visibilidad. Esto será evidente en las fotos que se presentan, en las que se representa a la víctima en el centro de la escena.

Como dijimos, un recurso utilizado en la fabricación de la víctima es la construcción de un "nosotros" que incluye a los lectores y a la víctima como parte de un mismo grupo social. Para ello se da cuenta de toda manifestación de 
afecto y solidaridad, lo que genera la idea de que se trataba de alguien popular, familiar y querido. Un primer grupo de fotografías intenta crear una cercanía social, moral y afectiva que propicia la identificación con la figura de la víctima. Para ello se presentan dos recursos particulares: poner a la/s víctima/s y sus familiares en el centro de la escena, y hacerlas ver con expresiones dolientes y con un entorno afectivo compuesto por muchos individuos. Esto pareciera utilizarse como un indicador de su valor social y de su “representatividad”. Observemos algunas imágenes:

Imagen 4

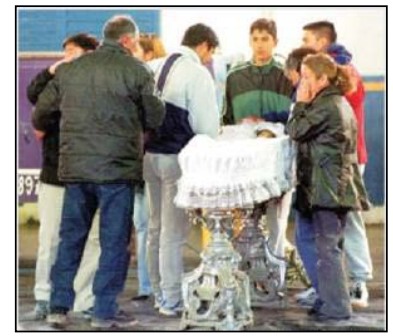

(Hoy, 15-06-2004)

Imagen 5

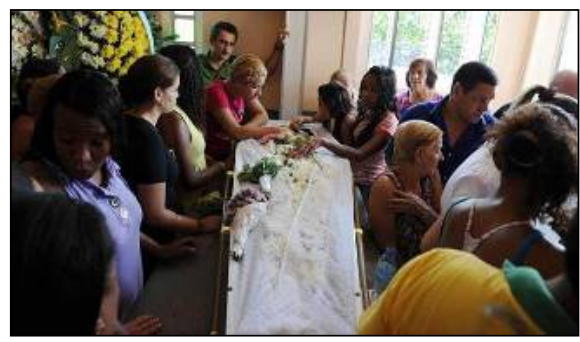

(El Día, 09-04-2011)

Asimismo, en un segundo grupo de fotografías se representan las manifestaciones de familiares de las víctimas en repudio a los episodios. Se trata de escenas tomadas en espacios abiertos de un plano entero. El recorrido visual está signado por el protagonismo de una gran cantidad de personas que llevan pancartas y letreros alusivos a las víctimas. Dichos grupos parecieran 
seguir más allá del espacio capturado por la cámara fotográfica. Son imágenes de personas civilizadas, en tanto buscan manifestar su dolor y solicitar seguridad y justicia. Veamos algunas formas en las que se presenta:

Imagen 6

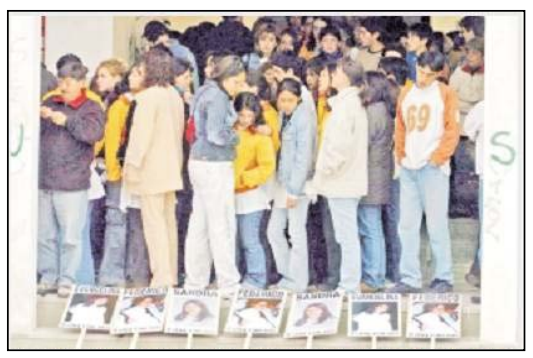

(Hoy, 05-10-2004)

Imagen 7

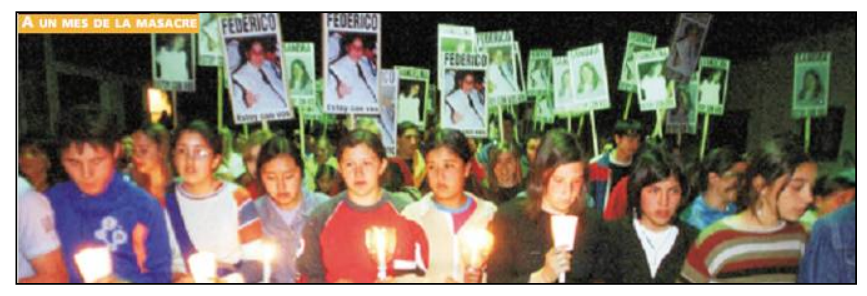

(Hoy, 29-10-2004)

Y por último, un tercer conjunto de fotografías representa el entorno cercano de las víctimas. Las imágenes distinguen como elemento visual de mayor protagonismo a individuos con gestos de caricias y abrazos. Así, el recorrido visual está trazado por el juego de las miradas y las expresiones entre los sujetos fotografiados. Esto pareciera representar el valor social y moral del entorno de la víctima como contenedor y afectivo. Este aspecto es asociado también con la representación de familia ideal. A continuación se presentan algunos ejemplos: 
Imagen 8

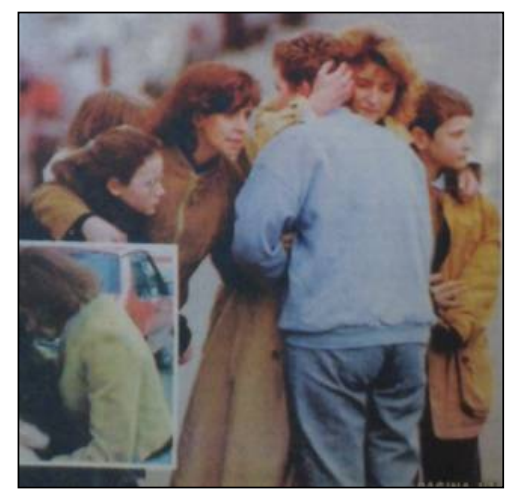

(Hoy, 14-03-1996)

Imagen 9

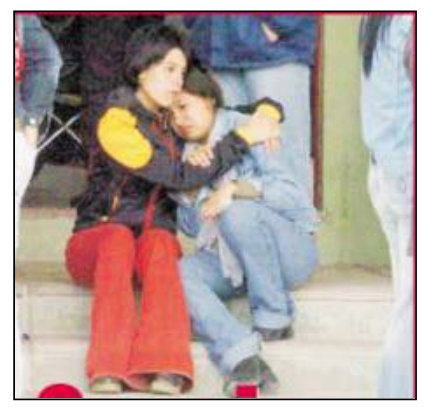

(Hoy, 05-10-2004)

Imagen 10

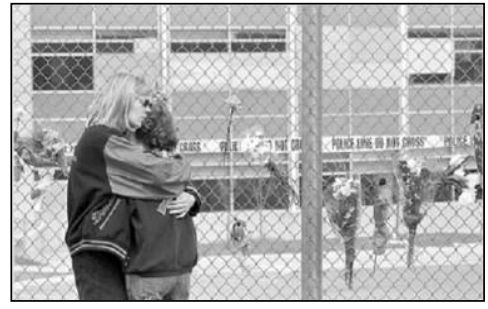

(Hoy, 29-09-2004)

Así también, la representación de los episodios se limita a la ejercida físicamente y en casos extremos y se evaden otros tipos de violencias más sutiles. 


\section{EFECTOS SIMBÓLICOS DEL DISCURSO DICOTÓMICO SOBRE EL ESPACIO ESCOLAR}

En los apartados anteriores se ha trabajado con las formas de designar, nominar y adjetivar al joven violento-joven no violento / alumno violentoalumno no violento, desde su contenido expreso e implícito (Kaplan, 2008b). Estas son de relevancia, dado que, como sostiene Bourdieu,

a través de estas propiedades, cuando son percibidas por agentes dotados de las categorías de percepción pertinentes (...), funcionan, en la realidad misma de la vida social, como signos: las diferencias funcionan como signos distintivos, y como signos de distinción positiva o negativa, y eso fuera mismo de toda intención de distinción. (1988: 136)

En este apartado nos centraremos en los efectos simbólicos producidos por la construcción de la noticia desde una mirada dicotómica. Frente a la presentación de los episodios como enfrentamientos entre dos bandos un primer efecto simbólico registrado es la simplificación y polarización del conflicto. Esta forma en la que se fabrican estos hechos abona a la construcción colectiva de una representación, que, aunque esté alejada de la realidad, perdura dado que fortalece las interpretaciones espontáneas, moviliza prejuicios y los redobla (Champagne, 1999).

Junto a Elias sostenemos que "La mayoría de los hombres de todas las sociedades tiene a su disposición toda una gama de expresiones para estigmatizar a otros grupos” (Elias, 1998: 96). En esta trama, un segundo efecto simbólico reconocido es la mirada de de peligrosidad sobre las bandas de jóvenes en tanto victimarios privilegiados del discurso mediático. Sin embargo, los jóvenes refuerzan sus identidades individuales en relación con otros jóvenes. Los grupos de pertenencia colectiva son fundamentales para la construcción identitaria del joven. Describe Kaplan: "Las bandas, que a los ojos 
de las generaciones adultas suelen ser percibidas como hordas de adolescentes salvajes, pueden ofrecerle a los jóvenes una socialización entre iguales y funcionar como válvula de escape ante las miradas estigmatizantes” (2012: 28). Ahora bien, Robert Muchembled advierte que esta asociación entre bandas juveniles y violencia está presente desde la Edad Media:

Durante su larga espera del matrimonio, tanto en los pueblos como en las ciudades, los mozos practican una cultura de bandas basada en la competición entre iguales para aumentar su valor ante las chicas y para compensar las forestaciones ligadas a ese estado incómodo, entre la infancia y una vida de adulto de pleno derecho. Su principal preocupación consiste en exaltar una virilidad que los hace existir ante los demás. (...) Entrenados para el combate y formados en una ética guerrera igualmente viril, los jóvenes nobles no se diferenciaban fundamentalmente de los plebeyos en ese terreno: no será hasta más tarde, durante el siglo XVI, cuando se inventan las reglas del duelo aristocrático. (Muchembled, 2010: 29)

En ese período, la violencia de los jóvenes no solo es admitida, sino también fomentada para generar una ética viril entre los campesinos, y sobre todo entre los nobles, que tienen la vocación de convertirse en guerreros: "Representa, por el contrario, un valor positivo, en el que se basan las jerarquías y que preside continuamente los intercambios, materiales y simbólicos. Es más, reina tanto en el universo lúdico como en el tiempo y el espacio del trabajo” (Muchembled, 2010: 65). Toda frontera entre lo que es violento y lo que no lo es resulta producto de una delimitación arbitraria de "la realidad” que

es totalmente social y las clasificaciones mas "naturales" se apoyan en rasgos que no tienen nada de natural y que, en gran parte, son producto de una imposición arbitraria, es decir, de un estado anterior a la relación de 
fuerza en el campo de las luchas por la delimitación legítima. (Bourdieu, 2014: 114)

Se ha observado cómo a través de esta modalidad y los sentidos implícitos en las coberturas se construye la condición estudiantil de algunos niños y jóvenes como amenazantes. La prensa platense crea y recrea una forma de sensibilidad específica frente a la problemática de la violencia, haciendo blanco de la responsabilidad a los niños y a jóvenes. Estos son nominados como sujetos amenazantes que sobrepasan los umbrales de tolerancia que asumiríamos como sociedad. En lugar de abordar a las infancias en peligro se adjudica el peligro a estas; jóvenes acosadores y peligrosos son imágenes reiteradas. La otredad se construye como amenaza.

El tratamiento mediático permite pensar el vínculo entre la violencia y las configuraciones sociales, fuera y dentro de la escuela (Castorina y Kaplan, 2006). Las prácticas discursivas mediáticas abordan y deslizan sentidos sobre la relación individuo-sociedad. Aparece representada la visión del sentido común sobre una cierta personalidad social deshistorizada, que no da cuenta de la dialéctica entre individuo y sociedad. Como sostiene Kaplan (2008a), es posible reconocer formas específicas de violencia en las instituciones escolares que, si bien no son un correlato directo de los mecanismos más amplios de desigualdad social y educativa, no pueden abordarse independientemente de estos. La existencia social y la existencia individual, la estructura social y la estructura psíquica, los comportamientos individuales y los comportamientos sociales, están íntimamente imbricados desde una perspectiva socio-histórica. Las víctimas son individuos en sociedad, que participan en ciertas configuraciones epocales (Debarbieux, 2002).

Un tercer efecto simbólico identificado es la sobrestimación negativa de la aparición de la violencia física entre alumnas. Esto se vincula con una construcción diferenciada en el caso de los alumnos. Este tipo de coberturas no permite abordar las múltiples dimensiones que atraviesan la sexualidad y la 
construcción de la subjetividad, la integridad del sujeto bio-psico-social, ni repensar la importancia de los roles asumidos por varones y mujeres, sino que más bien contribuyen a consolidar las significaciones hegemónicas sobre lo femenino y lo masculino, que se basan en discursos naturalizados. Así, se constituyen en un dispositivo que provoca el entrampamiento de las identidades de género en categorías con pretensión de "realidad natural”. Las estrategias simbólicas de la prensa no plantean periodísticamente el problema de la detección de la violencia y el abuso, la burocracia, la ineficiencia de los informantes profesionales, la insuficiencia del aparato estatal para detectar y actuar ante la denuncia de agresión, previa a ella y posterior a la misma.

Un cuarto efecto simbólico es la construcción de una cercanía moral y afectiva con las víctimas y sus familiares. Como dijimos, un recurso utilizado en la representación de la víctima es la construcción de un “nosotros” que incluye a los lectores y a la víctima como parte de un mismo grupo social. Para ello se da cuenta de toda manifestación de afecto y solidaridad, lo que genera la idea de que se trataba de alguien popular, familiar y querido. Un ejemplo se dio en el caso que los medios llamaron "La masacre de Río de Janeiro”. ${ }^{7}$ La cantidad de personas que fueron al velorio fue utilizada también como un indicador de su valor social y de su "representatividad". Otro recurso es la búsqueda y reproducción de los relatos de sus compañeros y familiares que dan cuenta de sus virtudes en tanto testigos de la calidad humana de la víctima. En este sentido hay un correlato con la figuración de ciertos sujetos como establecidos en el discurso mediático y otros forasteros, donde "los miembros de grupos que son más poderosos que otros grupos interdependientes creen de sí mismos que son humanamente mejores que otros” (Elias, 1998: 81), y con la caracterización de los victimarios como “personas de valor humano inferior”

\footnotetext{
${ }^{7}$ Refiere a un suceso ocurrido el 7 de abril de 2011, en el que Wellington Menezes de Oliveira, de 23 años, en su condición de ex alumno entró a la escuela primaria municipal Tasso da Silveira de Río de Janeiro y mató a doce alumnos e hirió a más de veintidós. Luego se suicidó. La cobertura del hecho se realizó por los cuatro diarios relevados desde el 7 al 16 de abril de 2011.
} 
(Elias, 1998: 81). En continuidad con estas formas de designación, Patrick Champagne (1999) considera que algunos sujetos son menos aptos para controlar la representación de sí mismos en las coberturas mediáticas. Este aspecto constituye un "círculo vicioso" que da poco lugar al discurso de los dominados, ya que son los más difíciles de escuchar, y se habla de ellos más de los que ellos hablan. Lejos de ayudarlos, la intervención de los periodistas suele crear una imagen negativa. Contribuyen a su estigmatización, sin duda involuntaria y resultante del funcionamiento mismo del campo periodístico, que se extiende más allá de los acontecimientos que provocan.

Aquí nos interrogamos sobre el par inclusión-exclusión, el “ellos” y el "nosotros" presentes en las notas. La representación que estas construyen se realiza sobre procesos de diferenciación-identificación centrados en pares dicotómicos jerárquicos: normal-anormal, civilizado-bárbaro, rico-pobre y blanco-negro. Las nominaciones y adjetivaciones socialmente peyorativas con las cuales se mencionan y/o describen a quienes consideran "violentos" operan como actos de clasificación social que los ubican en posiciones inferiores del espacio social y simbólico. Las clasificaciones sociales operan sobre todo a través de oposiciones dualistas y organizan la percepción del mundo social.

Los sistemas de valores éticos y estéticos que se encuentran depositados, listos para funcionar de manera casi automática, en las parejas de adjetivos antagónicos o la misma lógica del lenguaje culto cuyo valor total reside en una diferencia, es decir, en la distancia con respecto a las maneras simples y comunes de hablar: las figuras, en tanto que modificaciones del uso ordinario, son de alguna manera la objetivación de la relación social en la que se producen y funcionan, y resulta perfectamente vano buscar en el ser mismo de los tropos que enumeran los tratados de retórica unas propiedades que, como todas propiedades de distinción, no existen más que en y por la relación, en y por la diferencia (Bourdieu, 1991: 224). 
La presentación del discurso mediático en víctimas y victimarios no puede dar cuenta de la complejidad de las situaciones en las que intervienen otros procesos, que se resisten a ser explicados en términos de opuestos. Los victimarios en edad escolar del discurso mediático son, en muchos casos, víctimas de la exclusión. Esto lleva a pensar la construcción de la presentación de los alumnos a través de los discursos individualizantes y auto responsabilizadores. Su fuerza reside en que a través de modos sutiles, pero no por ello menos eficientes, impactan sobre las formas de pensar, actuar y sentir de los sujetos, esto es, sobre la producción de subjetividad (Kaplan, 2006, 2009 y 2013).

La presentación dicotómica de los episodios escolares tiene eficacia ideológica porque remite a oposiciones fundamentales del orden social, entre dominantes y dominados.

Todos los agentes de una formación social determinada tienen en común, efectivamente, un conjunto de esquemas de percepción fundamentales, que reciben en un comienzo de objetivación en las parejas de adjetivos antagónicos comúnmente empleados para clasificar y calificar a las personas o los objetos en los campos más diferentes de la práctica. Matriz de todos los lugares comunes, que si se imponen tan fácilmente es porque tienen a su favor todo el orden social, la red de oposiciones (...), [que] tiene como principio la oposición entre la "elite" de los dominantes y la "masa" de los dominados, multiplicidad contingente y desordenada, intercambiable e innumerable, débil y desarmada, sin otra existencia que para la estadística (Bourdieu, 1991: 479).

Kaplan, Krotsch y Orce (2012) historizan la mirada social estigmatizante, incluso racista, que se ha construido respecto a los jóvenes en contextos de fuerte diferenciación y desigualdad, demostrando que subyace un discurso social que intenta imponerse como verdad. La imagen de lo juvenil subalterno como delincuencial tiene raíces profundas en nuestra matriz social. Los autores 
muestran cómo la mirada social de peligrosidad que se construye sobre los jóvenes se correlaciona con la historia de la violencia.

Un quinto efecto simbólico es la disolución de la responsabilidad adulta. Como define Sergio Balardini los adultos, a pesar de los cambios en las dinámicas socioculturales, tienen funciones esenciales. En palabras del autor:

En cuanto a las atribuciones modernas del rol de adulto (que desde luego podrán discutirse pero no obviarse), la siguientes cuatro aparecen como las fundamentales: protección, provisión, proyección y transmisión. Si nos preguntamos en cada caso cómo es la intervención de los adultos, nos encontraremos con que las ejercen con menos intensidad y presencia, e incluso en muchos casos quienes las ejercen, cómo pueden y en las condiciones que les ha tocado, son los niños o adolescentes mismos. Pareciera que ha llegado la hora de preguntarnos sobre el modo de ser adulto hoy, sobre las distintas "adulteces", y matizar un poco la pregunta sobre las adolescencias (Balardini, 2013: 197)

Las estrategias simbólicas que operan en los discursos individualizantes proponen una mirada dicotómica, invisibilizan la responsabilidad adulta y diluye la identidad ciudadana. Las luchas simbólicas por los actos de clasificación social y el posicionamiento dentro del espacio socialmente jerarquizado pueden observarse en la presentación de la juventud como riesgo. Sin hacer visibles sus derechos, se la considera como problema que se corrige y no como potencialidad que se promueve. Asimismo, la "magia" del lenguaje en los discursos construye espacios de significación acerca de la juventud que son orientados de acuerdo a los intereses adultos. Estos espacios establecen representaciones que, lejos de integrar, fraguan fronteras intergeneracionales.

$\mathrm{Y}$ un sexto efecto simbólico es la tendencia punitiva y disciplinaria para tramitar los problemas en el espacio escolar. La presentación dicotómica de los episodios violentos en el espacio escolar puede inducir a una resolución punitiva de los conflictos sociales. En este sentido develar las formas de 
presentación del discurso social de los medios de comunicación puede llevarnos a pensar en formas alternativas de resolución de conflictos, como el modelo comunitarista (Patiño Mariaca y Ruiz Gutiérrez, 2015) que exige diseños normativos, políticos y sociales que rebasen el marco de los componentes punitivos convencionales de persecución y castigo a los victimarios, y se orienta, en cambio, a la implementación de mecanismos reales de reparación fundados en la responsabilidad y la solidaridad respecto a las víctimas y los victimarios.

Esto sucede en una temporalidad educativa de ampliación de la obligatoriedad. Como ya se mencionó en apartados anteriores, desde 1993 hubo un cambio en la política de obligatoriedad educativa en la Argentina. Con la sanción de la Ley Federal de Educación, y luego con la Ley de Educación Nacional de 2006 se amplía los años de escolaridad obligatoria de los estudiantes. Con este cambio en la política educativa, se está frente a la primera generación de muchos jóvenes que tienen la posibilidad de acceder a este más años de enseñanza oficial. Distribuida de manera desigual, la ampliación de la cobertura de la escuela obligatoria pone de manifiesto la necesidad de construir herramientas específicas para procesos de expansión de los sistemas, tomando en cuenta no sólo lo referido a lo presupuestario sino también revisando los problemas relacionados con la enseñanza en este nivel así como las cuestiones vinculadas a la organización institucional y los puestos de trabajo docente (UNICEF, 2014). El ingreso de sectores de la población a las escuelas secundarias que nunca antes habían accedido a ella y para los cuales no estuvieron destinadas desde su creación pone en evidencia la necesidad de repensar sus formatos organizacionales. La tradición de la escuela secundaria argentina, eminentemente selectiva y destinada a la formación de las capas medias ya sea para permitir la prosecución de los estudios superiores o para la formación para determinados tipos de trabajo (con la consecuente transmisión de valores asociados a ellas tales como la disciplina, el aprovechamiento del 
tiempo, el esfuerzo individual, entre otras cuestiones), choca con el ingreso masivo de otros grupos con otras culturas, trayectorias de vida y expectativas.

En síntesis, la presentación dicotómica del par víctima-victimario apoya varias de las creencias instaladas y legitimadas dificultando en los lectores la generación de una representación que supere la mirada dicotómica. No hay protagonistas colectivos visibles de los hechos de violencia en el espacio escolar, pero tampoco hay responsables de la no violencia, sólo hay víctimas y victimarios. Así también, estos modos comunicacionales invisibilizan las burlas y cargadas, que son presentadas por los estudiantes como situaciones cotidianas y habituales entre ellos (di Nápoli, 2012; Mutchinick, 2013) menos evidentes, más lentas pero no menos nocivas.

\section{CONCLUSIONES}

El presente estudio permitió un avance en la conceptualización de los desafíos en la visibilización de los episodios de violencia en los espacios escolares en los medios de comunicación. El análisis socioeducativo del discurso constituye una herramienta privilegiada para estudiar de qué manera los discursos sociales, en este caso el de la prensa, sostienen un ordenamiento y una determinada clasificación del mundo, de sus eventos y de sus participantes.

Desde una perspectiva socioeducativa se ha caracterizado y analizado la presentación dicotómica del par víctima victimario en los discursos mediáticos platenses sobre la los episodios de violencia en las escuelas producidas por la prensa escrita de la ciudad de La Plata, en el período de 1993-2011. Se analizaron las coberturas en relación con las categorías "alumno violento" y “alumno no violento” y se describió cómo los comportamientos tipificados de violentos son relacionados con otros atributos (personales y sociales) a partir de los cuales se construye una representación diferenciada entre jóvenes violentos 
y jóvenes no violentos. En la lucha por la producción del sentido de los episodios se observan estrategias diferenciales de producción de visibilidad. Cuando se nombra y alude a la figura de la víctima, los medios dan cuenta de una cercanía social, moral y hasta afectiva que propicia la identificación con su figura.

Para ello observo una serie de recursos particulares: prevalece la identidad educativa, se presentan voces de los familiares de las víctimas y se construye un "nosotros" que incluye a los lectores. Las imágenes fotográficas tuvieron como función visibilizara las víctimas y sus familiares como dolientes. Otras hicieron énfasis en mostrar su valor social y su "representatividad". Presentan a la/s víctima/s y sus familiares con expresiones dolientes y con un entorno afectivo compuesto por muchos individuos. Esto contribuye en establecer la proximidad social, moral y afectiva. En estas formas de cubrir los acontecimientos, se evidencia la dificultad para la representación de ciertos sujetos. Los recursos enunciativos para representar al victimario y que proponen una distancia simbólica son: la certeza de inculpación y el accionar de alumnos en bandas. En las prácticas discursivas se construyen una imagen de un "nosotros" adjudicándose un mayor valor social o superior, mientras que a través de la caracterización del victimario se ponen en juego una serie de categorías estigmatizantes, ya disponibles en el entramado social, con las que catalogan a ciertos jóvenes como de menor valor social.

En continuidad con los estudios de juventud (Urresti, 2000; Balardini, 2004; Chaves, 2005; Saintout 2013), se evidencia que hay una representación de sujetos peligrosos a través de estrategias comunicativas. La presentación dicotómica del par víctima - victimario es una forma del discurso dóxico de la prensa platense, donde se hacen visibles las dinámicas sociales de la estigmatización.

Así también, en acuerdo con investigaciones anteriores (Valdemarca y Bonavitta, 2011; Saez, 2013) se aporta evidencia empírica sobre la mirada 
dicotómica de víctima- victimario en l mediatización de los episodios violentos en la prensa argentina. En estas formas de designación, con las que se pretende reducir a algo homogéneo fenómenos extremadamente complejos, quedan ubicados en primer plano aquellos aspectos de las violencias que se asocian con las explicaciones realizadas en términos de “anomalías" individuales, de “desviaciones" de la norma, “deficiencias” y “carencias". Uno de los modos privilegiados para producir esta operación consiste en convertir la violencia en una sustancia carente de un entramado de relaciones históricas y sociales que la sostengan. En las coberturas estudiadas los sentidos se construyen desviando la discusión de los problemas estructurales, resumiendo las violencias en el espacio escolar y simplificando la cuestión con el antagonismo civilizaciónbarbarie, víctima-victimario.

En continuidad con los estudios de Gentili (2011) se observa que los procedimientos enunciativos de las noticias se convierten en una ocasión propicia para que los medios masivos de comunicación pongan en escena la figura mediática del joven (varón) de sectores populares asociado a la violencia. Sin embargo en las coberturas sobre la violencia en los espacios escolares. Aparece como ruptura la figura de la alumna violenta, donde se observa un cambio en la identificación femenina con la pasividad y la amabilidad.

Así, se ha aportado como novedoso el estudio de la presentación dicotómica del par víctima-victimario como dinámica de estigmatización en el espacio escolar. Esta forma de presentación de los episodios visibiliza el deterioro de la calidad de la información. Los cambios operados en los últimos años en la construcción de la noticia permiten desentrañar la circulación de discursos informativos que buscan otorgar a un sector de la población estudiantil la responsabilidad de la inseguridad en las escuelas. En las prácticas discursivas se homologan casos de violencia en el espacio escolar de origen variado. Hay una narración donde no se recupera la historicidad del caso particular, y se observa una igualdad de las condiciones de los individuos en el 
plano discursivo que no se ve reflejada en las condiciones de vida. Así, la prensa platense tiende a presentar el fenómeno de las violencias en el espacio escolar sin contextualizar ni ofrecer información que permita saber las circunstancias personales que llevan a cada actor a realizar las acciones que son narradas y visualizadas.

En síntesis, en las prácticas discursivas de la prensa platense se delimitan fronteras territoriales y simbólicas que asocian los episodios de violencia en el espacio escolar de forma diferenciada. Es necesario que los actores del sistema escolar reflexionen sobre ¿Cómo se representa a la escuela como espacio social de formación en los medios de comunicación? En una temporalidad educativa de ampliación de la obligatoriedad de los jóvenes ¿Cómo se representa la condición estudiantil? ¿Qué relaciones establece la opinión pública entre los jóvenes y la violencia? Reconstruir estos procedimientos permite desandar el camino de la naturalización para dar cuenta críticamente de uno de los mecanismos más importantes de construcción social del sentimiento de inseguridad en las escuelas y de sus consecuencias en el tratamiento de la condición estudiantil. Creemos significativo destacar la relevancia de esta investigación en tanto amplía la base empírica de las formas de presentación de la condición estudiantil en el discurso mediático desde una perspectiva socioeducativa. Es importante que los medios de comunicación participen en el desarrollo de nuevas sensibilidades y disposiciones hacia los estudiantes como sujetos de derecho, contribuyendo a renovar el compromiso social con una sociedad más democrática y más justa.

\section{REFERENCIAS BIBLIOGRÁFICAS}

Balardini, Sergio (2004). Políticas de juventud en argentina: balance y perspectivas. En E. Gerber y S. Balardini (Coord.) Políticas de Juventud en Latinoamérica: Argentina en perspectiva. Buenos Aires: Fundación Friedrich Ebert. 
Balardini, Sergio (2013). La experiencia intergeneracional de los nativos paritarios. En Carina V. Kaplan y Claudia Bracchi (Comp.) Imágenes y discursos sobre los jóvenes. La Plata: UNLP

Barbosa Martínez, Amalia (2006). Sobre el método de la interpretación documental y el uso de las imágenes en la sociología: Karl Mannheim, Aby Warburg y Pierre Bourdieu. Sociedade e Estado, N²1. Brasilia: Universidade de Brasília- Departamento de Sociologia.

Bonilla Vélez, Jorge Iván y Tamayo Gómez, Camilo Andrés (2007). Las violencias en los medios, los medios en las violencias. En publicacion: Las violencias en los medios, los medios en las violencias. CINEP, Fundacion Centro de Investigacion y Educacion Popular, Bogotá: Colombia. ISBN 978 - 958 - 44 - 0288 - 2. Disponible en: http://bibliotecavirtual.clacso.org.ar/ar/libros/colombia/cinep/textos/viol enciamedios.pdfconsultado en marzo 2012.

Bourdieu, Pierre (1988). Espacio social y poder simbólico. En P. Bourdieu, Cosas Dichas. Buenos Aires: Gedisa.

Bourdieu, Pierre (1991). La distinción. Criterio y bases sociales del gusto. Madrid: Taurus Humanidades.

Bourdieu, Pierre (2002). Cuestión de Palabras. Una visión más modesta del rol de los periodistas. Intervención en coloquio de Periodistas sin fronteras, publicada en (1992). Les mensonges du Golfe [Las mentiras del Golfo]. París: Arlèa. Esta conferencia se encuentra traducida en la recopilación Bourdieu, P. (2005). Pensamiento y acción. Buenos Aires: Libros del Zorzal.

Bourdieu, Pierre (2014). ¿Qué significa hablar? Economía de los intercambios lingüísticos. Buenos Aires: Akal. 
Bourdieu, Pierre y Wacquant, Louis (2005). El propósito de la sociología reflexiva. En Pierre Bourdieu, Una invitación a la sociología reflexiva. Buenos Aires: Siglo XXI.

Castorina, José Antonio y Kaplan, Carina Viviana (2009). Civilización, violencia y escuela. Nuevos problemas y enfoques para la investigación. En Carina V. Kaplan (Dir.). Violencia escolar bajo sospecha. Buenos Aires: Miño y Dávila

Cerbino, Mario (2012). El lugar de la violencia. Perspectivas críticas sobre pandillerismo juvenil. Quito: Taurus.

Champagne, Patrick (1999). La visión mediática. En P. Bourdieu. La miseria del mundo. Buenos Aires: Fondo de Cultura Económica.

Chaves, Mariana (2005). Juventud negada y negativizada: Representaciones y formaciones discursivas vigentes en la Argentina contemporánea. Última Década N²3. Valparaíso: Ediciones CIDPA.

Debarbieux, Eric (2002). Violências nas escolas': divergências sobre palavras e um desafio politico. En Eric Debarbieux y Catherine Blaya (Eds.). Violência nas escolas e políticas públicas. Brasilia: UNESCO.

di Nápoli, Pablo (2012). Jóvenes, violencia y escuela: un análisis de las relaciones entre grupos de pares en dos escuelas secundarias de la Argentina. Revista Austral de Ciencias Sociales No23. Chile: Universidad Austral de Chile. Facultad de Humanidades. Instituto de Ciencias Sociales.

Elias, Norbert (1998). Ensayo teórico sobre las relaciones entre establecidos y marginados. En La civilización de los padres y otros ensayos. Bogotá: Norma. P. 79-138.

Elias, Norbert (2009). El proceso de la civilización. México: Fondo de Cultura Económica. 
Fairclough, Norman (2008). El análisis del discurso y la mercantilización del discurso público: las universidades. Discourse y SocietyN². Estados Unidos de América: SAGE Publications.

Finocchio, Silvia (2009). La escuela en la historia argentina. Buenos Aires: Edhasa.

Gentili, Florencia (2011). Los procedimientos discursivos para la construcción mediática de la figura del joven pobre y delincuente el caso jonathan. Última Década No34. Valparaíso: Ediciones CIDPA.

Rey, Germán (2005). El cuerpo del delito. Representación y narrativas mediáticas de la seguridad ciudadana. Colombia: Centro de competencia en comunicación para América Latina.

Goffman, Erving (2001). Estigma la identidad deteriorada. Buenos Aires: Amorrortu.

Kaplan, Carina Viviana (2006). Violencias en plural. Sociología de las violencias en la escuela. Buenos Aires: Miño y Dávila.

Kaplan, Carina Viviana (2008a). Comportamiento individual y estructura social: cambios y relaciones. Una lectura desde Norbert Elias. En Carina V. Kaplan (coord.), La civilización en cuestión. Escritos inspirados en la obra de Norbert Elias. Buenos Aires: Miño y Dávila.

Kaplan, Carina Viviana (2008b). Talentos, dones e inteligencias. El fracaso escolar no es un destino. Buenos Aires: Colihue.

Kaplan, Carina Viviana (Dir.) (2009). Violencia escolar bajo sospecha. Buenos Aires: Miño y Dávila.

Kaplan, Carina Viviana (2011). Jóvenes en turbulencia. Miradas críticas contra la criminalización de los estudiantes. Propuesta Educativa N³5. Buenos Aires: Miño y Dávila Editores - Centro de Publicaciones Educativas y Material Didáctico SRL. 
Kaplan, Carina Viviana. (2012). Mirada social, exclusión simbólica y autoestigmatización. En Carina V. Kaplan, Lucas Krotsch y Victoria Orce Con ojos de joven. Relaciones entre desigualdad, violencia y condición juvenil Buenos Aires: Editorial de la Facultad de FFyL- UBA, pp. 15-78

Kaplan, Carina Viviana (2013). El miedo a morir joven. Meditaciones de los estudiantes sobre la condición humana. En Carina V. Kaplan (Dir.), Culturas estudiantiles. Sociología de los vínculos en la escuela. (págs. 45-68). Buenos Aires: Miño y Dávila.

Kaplan, Carina Viviana, Krotsch, Lucas y Orce, Victoria (2012). Con ojos de joven. Relaciones entre desigualdad, violencia y condición juvenil. Buenos Aires: Editorial de la Facultad de Filosofía y Letras, UBA.

Kessler, Gabriel (2009). El sentimiento de inseguridad, Buenos Aires: Siglo XXI.

Lahire, Bernard(1999). L'invention de l'illettrisme: rhétorique publique, éthique et stigmates. La Découverte: París.

Martín Criado, Enrique (2014). Mentiras, inconsistencias y ambivalencias.

Teoría de la acción y análisis de discurso. Revista Internacional de Sociología, $N^{\circ}$ 72. España: Consejo Superior de Investigaciones Científicas. Departamento de Publicaciones.

Muchembled, Robert (2010.Una historia de la violencia. Del final de la Edad Media a la actualidad. Buenos Aires: Paidós.

Mutchinick, Agustina (2013). Las incivilidades como dimensión simbólica de las violencias en la escuela. Un estudio socioeducativo sobre las relaciones de humillación desde la perspectiva de los estudiantes de educación secundaria. Tesis doctoral en Educación no publicada. Universidad de Buenos Aires. Argentina.

Observatorio de Jóvenes Comunicación y Medios, de la UNLP (2011). Informe 2011: Los jóvenes según los medios: introducción. Disponible en: 
http://www.perio.unlp.edu.ar/observatoriodejovenes/?q=node/89última consulta: 25/06/2010.

Observatorio de Jóvenes Comunicación y Medios, de la UNLP. (2009): $\begin{array}{llll}\text { Informe } & \text { resultados } & 2009 . & \text { Disponible }\end{array}$ en:http://www.perio.unlp.edu.ar/observatoriodejovenes/sites/perio.unlp. edu.ar.observatoriodejovenes/files/informe\%20entero\%20\%20puntos\%201\%20a\%204.pdf última consulta: 5/07/2010.

Patiño Mariaca, Daniel Mauricio, y Ruiz Gutiérrez, Adriana María. (2015). La justicia restaurativa: un modelo comunitarista de resolución de conflictos. Revista de la Facultad de Derecho y Ciencias Políticas $\mathrm{N}^{\circ}$ 45. Colombia: Universidad Pontificia Bolivariana.

Pegoraro, Juan (2000). Violencia delictiva, inseguridad urbana. La construcción social de la inseguridad urbana. Nueva Sociedad $N^{\circ}$ 167. Argentina: Editorial Nueva Sociedad.

Raiter, Alejandro y Zullo, Julia (Comp.) (2008). La caja de Pandora. La representación del mundo de los medios. Buenos Aires: La Crujía y Facultad de Filosofía y Letras, UBA.

Reguillo, Roxana (2006). Memoria, performatividad y catástrofes: ciudad interrumpida. Contratexto N4.Lima: Universidad de Lima. Facultad de Comunicación.

Saez, Virginia (2013). Prácticas discursivas e imágenes mediáticas sobre las violencias en los espacios escolares. Un análisis socioeducativo de la taxonomía alumno violento / alumno no violento en los medios gráficos de La Plata. Tesis de Maestría en Educación: Pedagogías críticas y problemáticas socioeducativas, no publicada, Facultad de Filosofía y Letras, Universidad de Buenos Aires. Argentina.

Saez Virginia (2015). Una mirada a la investigación sobre medios, violencia y escuela. Entramado №11. Colombia: Universidad Libre de Colombia. 
Saintout, Florencia (2013). Los jóvenes argentinos: desde una epistemología de la esperanza. Quilmes: Editorial UNQ.

UNICEF (2014). Acerca de la obligatoriedad en la escuela secundaria argentina. Análisis de la política nacional. Elena Duro: Dirección General. Disponible en: https://www.unicef.org/argentina/spanish/doc_final_30_08.pdf

Urresti, Marcelo (2000). Cambio de escenarios sociales, experiencia juvenil urbana y escuela. En Una escuela para los adolescentes. Buenos Aires: Unicef.

Valdemarca, Laura, y Bonavitta, Paola. (2011). La violencia intrafamiliar como representación en la prensa gráfica en el diario de mayor distribución en el interior de Argentina. Revista de Estudios Sociales N³9. Colombia: Universidad de los Andes.

Van Dijk, Tadeu (2007). Discurso racista. En Juan José Igartua y Carlos Muñiz (eds.). Medios de comunicación y sociedad. Salamanca: Ediciones Universidad de Salamanca.

Verón, Eliseo (1987). Prefacio a la segunda edición. En Construir el acontecimiento. Buenos Aires: Gedisa.

Wacquant, Louis (2010). Las cárceles de la miseria. Buenos Aires: Manantial.

Recepción de artículo: mayo 2017

Fecha de aceptación: noviembre 2017 